Pacific Journal of Mathematics

A COUNTEREXAMPLE IN THE THEORY OF DEFINABLe 


\section{A COUNTEREXAMPLE IN THE THEORY OF DEFINABLE AUTOMORPHISMS}

\section{MARTIN Ziegler}

As it is well known, the groups of definable automorphisms of two elementary equivalent relational structures satisfy the same $\forall_{1}$-statements. We show that this does not hold in general for $\forall_{2}$-statements, thus correcting an error in the literature.

0. An automorphism $\varphi$ of a model $\mathfrak{M}$ is said to be definable if there is a formula $H$ of the (first-order) language of $\mathfrak{M}$ and elements $a_{1}, \cdots, a_{n} \in M$, such that for all $x, y \in M$

$$
\mathfrak{M} \mid=H\left(x, y, a_{1}, \cdots, a_{n}\right) \quad \text { iff } \quad \varphi(x)=y .
$$

Let Def Aut $(\mathfrak{M})$ denote the group of definable automorphisms of $\mathfrak{M}$ (see [5]).

In [1] it is remarked that if $\mathfrak{M}$ and $\mathfrak{N}$ are elementary equivalent, then Def Aut $(\mathfrak{M})$ and Def Aut $(\mathfrak{N})$ are universally equivalent. In this note we show that this is the best possible result. We give an example of an $\forall \exists$-statement, which holds in Def Aut $(\mathfrak{M})$ but not in Def Aut $\left(\mathfrak{M}^{\prime}\right)$, where $\mathfrak{M}$ and $\mathfrak{M}^{\prime}$ are two elementary equivalent models. In fact our $\mathfrak{M}^{\prime}$ is an elementary extension of $\mathfrak{M}$. This disproves Theorems 1,2 in [3] (p. 109).

We construct our example from the Prüfer group $\mathbf{Z}\left(3^{\infty}\right)$ and investigate definability using the method of Ehrenfeucht games. statement

1. Our example is as follows. $H$ is the (group theoretical)

$$
\forall x \exists y x=y^{2}
$$

We define $\mathfrak{M}$ to be $(M, Z, \omega,<, f)$, where $M$ is the disjoint union of $Z$ and $\omega . Z$ is the underlying set of the Prüfergroup $Z\left(3^{\infty}\right)$, which is defined as

$$
\left\{\frac{n}{3^{m}} \mid n, m \in \mathbf{Z}\right\} / \mathbf{Z}
$$

$<$ is the natural ordering of $\omega$, the set of natural numbers. $f$ is a binary function defined by 


$$
\begin{aligned}
f(n, z):= & z+\frac{1}{3^{n}} Z \text { if } n \in \omega \text { and } z \in Z \\
& \left(+ \text { stands for the addition in } \mathbf{Z}\left(3^{\infty}\right)\right) \\
:= & 0(\in \omega) \text { otherwise. }
\end{aligned}
$$

We shall denote by $f_{n}$ the function

$$
\lambda z f(n, z): Z \rightarrow Z \quad(n \in \omega) .
$$

Every automorphism of $\mathfrak{M}$ operates on $\omega$ as the identity and therefore commutes with each $f_{n}$. The $f_{n}$ generate the group of all translations of $\mathbf{Z}\left(3^{\infty}\right)$, and so it is easily seen (see e.g. [4] p. 43) that the automorphisms of $\mathfrak{M}$ are just those permutations of $M$, which leave $\omega$ fixed and operate on $Z$ like a translation. Since the $f_{n}$ are definable, all automorphisms are definable and hence

$$
\operatorname{Def} \text { Aut }(\mathfrak{M}) \cong \mathbf{Z}\left(3^{\infty}\right) \mid=H \text {. }
$$

Let $\mathfrak{M}^{\prime}=\left(M^{\prime}, Z^{\prime}, W^{\prime},<^{\prime}, f^{\prime}\right)$ be an elementary extension of $\mathfrak{M}$ such that $W^{\prime} \neq \omega$. We claim that Def Aut $\left(\mathfrak{M}^{\prime}\right) \neq H$.

2. First we look at definability in $\mathfrak{M}$.

Every element $x$ of $\mathbf{Z}\left(3^{\infty}\right)$ has an unique representation

$$
x=\sum_{i=1}^{\infty} \frac{k_{i}}{3^{i}} \mathbf{Z}, k_{i} \in\{-1,0,1\}, \text { almost all } k_{i}=0
$$

We define

$$
\begin{aligned}
& |x|:=\sum_{i=1}^{\infty}\left|k_{i}\right|, v(x):=\max \left\{i \mid k_{i} \neq 0\right\} \quad \text { and } \\
& \bar{v}(x):=\min \left\{i \mid k_{i} \neq 0\right\}
\end{aligned}
$$

We note that

$$
\begin{aligned}
& \text { (i) }|-x|=|x| \\
& \text { (ii) }|x+y| \leqq|x|+|y| \\
& \text { (iii) }|x+y|=|x|+|y| \text { if } v(x)<\bar{v}(y) \\
& \text { (iv) } v(x+y) \leqq \max (v(x), v(y))
\end{aligned}
$$

Let $I_{n}$ be the set of all partial functions $\varphi$ from $Z$ in $Z$ with the following property:

$\operatorname{dom} \varphi$ is finite and for all $a, b \in \operatorname{dom} \varphi$

$$
|a-b| \leqq 2^{n} \quad \text { iff } \quad|\varphi(a)-\varphi(b)| \leqq 2^{n}
$$


and in this case $a-b=\varphi(a)-\varphi(b)$.

Clearly $I_{n+1} \subset I_{n}$ and if $\varphi \in I_{0}, a, b \in \operatorname{dom} \varphi$ and $f_{m}(a)=b$ then $f_{m}(\varphi(a))=\varphi(b)$.

We show that the family $I$ has the back and forth property: Let $\varphi \in I_{n+1}$ and $a \in Z \backslash \operatorname{dom} \varphi$. We want to extend $\varphi$ to $\varphi^{\prime} \in I_{n}$ with $\operatorname{dom} \varphi^{\prime}=\operatorname{dom} \varphi \cup\{a\}$.

There are two possible cases

(1) There is $b \in \operatorname{dom} \varphi$ such that $|a-b| \leqq 2^{n}$. Define $\varphi^{\prime}(a)$ : $=$ $\varphi(b)+(a-b)$. Then $\varphi^{\prime} \in I_{n}$. For let e.g. $c \in \operatorname{dom} \varphi$ and $|c-a| \leqq$ $2^{n}$. It follows from (i) and (ii)

$$
|b-c| \leqq|a-b|+|c-a| \leqq 2^{n}+2^{n}=2^{n+1}
$$

hence

$$
\begin{aligned}
& \varphi(b)-\varphi(c)=b-c . \quad \text { It follows } \\
& \varphi(c)-\varphi^{\prime}(a)=c-a .
\end{aligned}
$$

(2) For all $b \in \operatorname{dom} \varphi|a-b|>2^{n}$.

Choose $a^{\prime} \in Z$ such that $\left|a^{\prime}\right|>2^{n}$ and $\bar{v}\left(a^{\prime}\right)>v(\varphi(b))$ for all $b \in \operatorname{dom} \varphi$. Define $\varphi^{\prime}(a):=a^{\prime}$. From (iii) it follows that for all $b \in$ $\operatorname{dom} \varphi$

$$
\left|\varphi^{\prime}(a)-\varphi(b)\right|>2^{n}
$$

Since $\varphi^{-1} \in I_{n}$ iff $\varphi \in I_{n}$ it is clear that for all $\varphi \in I_{n+1}$ and $a \in Z$ there is an extension $\varphi^{\prime}$ of $\varphi$ such that $\varphi^{\prime} \in I_{n}, a \in r g \varphi^{\prime}$.

Let $H_{n}$ be the set of all formulas (of the language of $\mathfrak{M}$ ), which contain at most $n$ quantifiers and where all function symbols are applied to variables only. It is shown in [2] that, if $\varphi \in I_{n}, a_{1}, \cdots, a_{k} \in \operatorname{dom} \varphi$ $b_{1}, \cdots, b_{e} \in \omega$ and $H \in H_{n}$

$$
\begin{aligned}
& \mathfrak{M} \mid=H\left(a_{1}, \cdots, a_{k}, b_{1}, \cdots, b_{e}\right) \quad \text { iff } \\
& \mathfrak{M} \mid=H\left(\varphi\left(a_{1}\right), \cdots, \varphi\left(a_{k}\right), b_{1}, \cdots, b_{e}\right) .
\end{aligned}
$$

This is a consequence of the back and forth property.

Let now $z \in Z,|z|>2^{n}$ and $g$ be the translation

$$
\lambda x(x+z): Z \rightarrow Z \text {. }
$$

We show that $g$ is not definable using a formula in $H_{n}$. 
Assume that there is a $H \in H_{n}, a_{1}, \cdots, a_{k} \in Z, b_{1}, \cdots, b_{e} \in \omega$ such that for all $a, b \in Z$

$$
\mathfrak{M} \mid=H\left(a, b, a_{1}, \cdots, a_{k}, b_{1}, \cdots, b_{2}\right) \quad \text { iff } \quad g(a)=b .
$$

Choose $c \in Z$ such that $|c|>2^{n}$ and $\bar{v}(c)$ and $\bar{v}(2 c)$ are greater than all $v\left(a_{i}\right)$ and $v(z)$. (Choose a $c$ of the form $\left.\Sigma_{i=m}^{m^{\prime}} 1 / 3^{i}\right)$. Define $\varphi\left(a_{i}\right):=a_{i}$ $(i=1, \cdots, k), \varphi(c):=c$ and $\varphi(z+c):=z-c$. It is easily seen that $\varphi \in I_{n}$. For

$$
\begin{aligned}
& \left|(z+c)-a_{i}\right|=\left|z-a_{i}\right|+|c|>2^{n} \quad \text { by (iii), (iv)) } \\
& \left|(z-c)-a_{i}\right|=\left|z-a_{i}\right|+|-c|>2^{n} \quad \text { (by (i)) } \\
& |(z+c)-c|>2^{n} \\
& |(z-c)-c|=|z-2 c|=|z|+|2 c|>2^{n} \quad \text { (by (iii)). }
\end{aligned}
$$

Therefore we have, $\mathfrak{M} \vDash H\left(c, z-c, a_{1}, \cdots, b_{e}\right)$

$$
\text { since } \quad \mathfrak{M} \not \forall H\left(c, z+c, a_{1}, \cdots, b_{e}\right)
$$

Whence $z-c=z+c$ and we have the contradiction $c=0$.

We prove now that $M^{\prime} \mid=H$. First note that

$$
\left|\frac{1}{2} \cdot \frac{1}{3_{m}}\right|=\left|\sum_{i=1}^{m} \frac{-1}{3^{i}}\right|=m \text {. }
$$

This and the last result imply that for all $m>2^{n}$, $H\left(x, y, x_{1}, \cdots, x_{r}\right) \in H_{n}, a_{1}, \cdots, a_{r} \in M H\left(x, y, a_{1}, \cdots, a_{r}\right)$ does not define an automorphism $\psi$ of $\mathfrak{M}$ such that $\psi^{2}=f_{m} \cup i d_{\omega}$. This is expressible by a set of sentences which hold also in $\mathfrak{M}^{\prime}$. If we choose $m \in W^{\prime} \mid \omega$, we have for all $n \in \omega m^{\prime}>2^{n}$, hence $f_{m}^{\prime} \cup i d_{W}$, is a definable automorphism such that there is no definable automorphism $\psi \psi^{2}=f_{m}^{\prime} \cup i d_{w^{\prime}}$. Whence $M \not H$.

\section{REFERENCES}

1. J. Denes, Definable automorobisms in model theory I, (abstract), J. Symbolic Logic, 38 (1973), 354.

2. A. Ehrenfeucht, An application of games to the completeness problem for formalized theories, Fund. Math., 49 (1961), 129-141.

3. J. Grant, Automorphisms definable by formulas, Pacific J. Math., 44 (1973), 107-115.

4. B. Johnsson, Topics in Universal Algebra, Lecture Notes in Math. 250 (Berlin, Springer 1972) $220 \mathrm{pp}$.

5. W. E. Marsh, Definable automorphisms, Notices of Amer. Math. Soc., 16 (1969), 423.

Received May 27, 1974.

TEChNisChe Universitat BerLin 


\section{PACIFIC JOURNAL OF MATHEMATICS}

\section{EDITORS}

RICHARD ARENS (Managing Editor)

University of California

Los Angeles, California 90024

\section{J. DugundJI}

Department of Mathematics University of Southern California Los Angeles, California 90007

D. Gilbarg and J. Milgram

Stanford University

Stanford, California 94305

\section{ASSOCIATE EDITORS}
E. F. BECKENBACH
B. H. NeumanN
F. WoLF
K. YoshiDA

\section{SUPPORTING INSTITUTIONS}

\author{
UNIVERSITY OF BRITISH COLUMBIA \\ CALIFORNIA INSTITUTE OF TECHNOLOGY \\ UNIVERSITY OF CALIFORNIA \\ MONTANA STATE UNIVERSITY \\ UNIVERSITY OF NEVADA \\ NEW MEXICO STATE UNIVERSITY \\ OREGON STATE UNIVERSITY \\ UNIVERSITY OF OREGON \\ OSAKA UNIVERSITY
}

\author{
UNIVERSITY OF SOUTHERN CALIFORNIA \\ STANFORD UNIVERSITY \\ UNIVERSITY OF TOKYO \\ UNIVERSITY OF UTAH \\ WASHINGTON STATE UNIVERSITY \\ UNIVERSITY OF WASHINGTON \\ AMERICAN MATHEMATICAL SOCIETY
}

The Supporting Institutions listed above contribute to the cost of publication of this Journal, but they are not owners or publishers and have no responsibility for its contents or policies.

Mathematical papers intended for publication in the Pacific Journal of Mathematics should be in typed form or offset-reproduced (not dittoed), double spaced with large margins. Underline Greek letters in red, German in green, and script in blue. The first paragraph or two must be capable of being used separately as a synopsis of the entire paper. Items of the bibliography should not be cited there unless absolutely necessary, in which case they must be identified by author and Journal, rather than by item number. Manuscripts, in duplicate, may be sent to any one of the four editors. Please classify according to the scheme of Math. Reviews, Index to Vol. 39. All other communications should be addressed to the managing editor, or Elaine Barth, University of California, Los Angeles, California, 90024.

100 reprints are provided free for each article, only if page charges have been substantially paid. Additional copies may be obtained at cost in multiples of 50 .

The Pacific Journal of Mathematics is issued monthly as of January 1966. Regular subscription rate: $\$ 72.00$ a year (6 Vols., 12 issues). Special rate: $\$ 36.00$ a year to individual members of supporting institutions.

Subscriptions, orders for back numbers, and changes of address should be sent to Pacific Journal of Mathematics, 103 Highland Boulevard, Berkeley, California, 94708.

PUBLISHED BY PACIFIC JOURNAL OF MATHEMATICS, A NON-PROFIT CORPORATION Printed at Jerusalem Academic Press, POB 2390, Jerusalem, Israel.

$$
\begin{gathered}
\text { Copyright (C) } 1975 \text { Pacific Journal of Mathematics } \\
\text { All Rights Reserved }
\end{gathered}
$$




\section{Pacific Journal of Mathematics}

\section{Vol. 58, No. $2 \quad$ April, 1975}

Zvi Artstein and John Allen Burns, Integration of compact set-valued functions . . . . . . . . . 297

Mark Benard, Characters and Schur indices of the unitary reflection group $[321]^{3} \ldots \ldots \ldots . .309$

Simeon M. Berman, A new characterization of characteristic functions of absolutely continuous

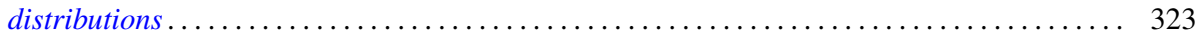

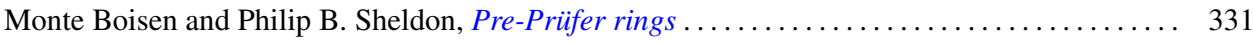

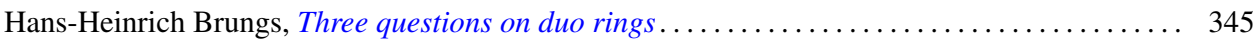

Iracema M. Bund, Birnbaum-Orlicz spaces of functions on groups................. 351

John D. Elwin and Donald R. Short, Branched immersions between 2-manifolds of higher

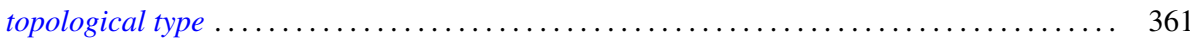

Eric Friedlander, Extension functions for rank 2, torsion free abelian groups . .......... 371

Jon Froemke and Robert Willis Quackenbush, The spectrum of an equational class of

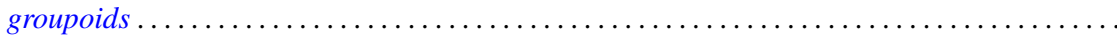

Barry J. Gardner, Radicals of supplementary semilattice sums of associative rings ...........

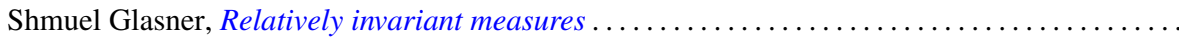

George Rudolph Gordh, Jr. and Sibe Mardesic, Characterizing local connectedness in inverse

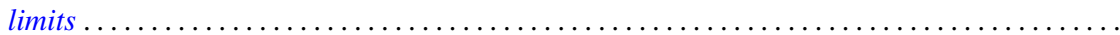

Siegfried Graf, On the existence of strong liftings in second countable topological spaces......

Stanley P. Gudder and D. Strawther, Orthogonally additive and orthogonally increasing

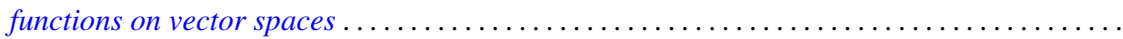

Darald Joe Hartfiel and Carlton James Maxson, A characterization of the maximal monoids and

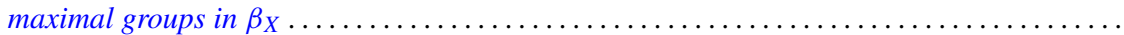

Robert E. Hartwig and S. Brent Morris, The universal flip matrix and the generalized faro-shuffle. .

William Emery Haver, Mappings between ANRs that are fine homotopy equivalences. .

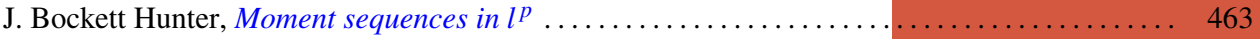

Barbara Jeffcott and William Thomas Spears, Semimodularity in the completion of a poset.... 467

Jerry Alan Johnson, A note on Banach spaces of Lipschitz functions . . . . . . . . . . . . 475

David W. Jonah and Bertram Manuel Schreiber, Transitive affine transformations on

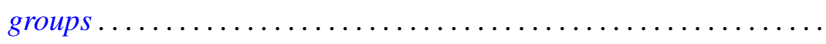

Karsten Juul, Some three-point subset properties connected with Menger's characterization of

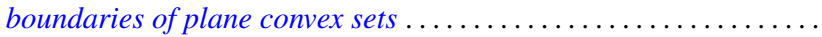

Ronald Brian Kirk, The Haar integral via non-standard analysis . . . . . . . . . . . . . 517

Justin Thomas Lloyd and William Smiley, On the group of permutations with countable

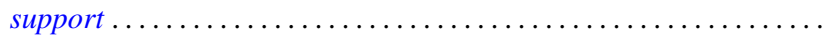

Erwin Lutwak, Dual mixed volumes .................................. 531

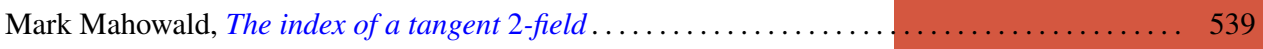

Keith Miller, Logarithmic convexity results for holomorphic semigroups . . . . . . . . . . . . 549

Paul Milnes, Extension of continuous functions on topological semigroups . . . . . . . . . . 553

Kenneth Clayton Pietz, Cauchy transforms and characteristic functions ................ 563

James Ted Rogers Jr., Whitney continua in the hyperspace $C(X) \ldots \ldots \ldots \ldots \ldots \ldots \ldots \ldots .569$

Jean-Marie G. Rolin, The inverse of a continuous additive functional . . . . . . . . . . . . 585

William Henry Ruckle, Absolutely divergent series and isomorphism of subspaces . ........ 605

Rolf Schneider, A measure of convexity for compact sets . ..................... 617

Alan Henry Schoenfeld, Continous measure-preserving maps onto Peano spaces .......... 627

V. Merriline Smith, Strongly superficial elements .......................... 643

Roger P. Ware, A note on quadratic forms over Pythagorean fields . . . . . . . . . . . . . . 651

Roger Allen Wiegand and Sylvia Wiegand, Finitely generated modules over Bezout rings . . . . 655

Martin Ziegler, A counterexample in the theory of definable automorphisms . . . . . . . . . 665 